\title{
Autopsia pediátrica en tiempos de la COVID-19 ¿ser o no ser?
}

\section{Pediatric autopsy in times of COVID-19, to be or not to be?}

Rodolfo Rodríguez-Jurado

\begin{abstract}
¿Que es más noble para el espíritu? ¿Sufrir los golpes y dardos de la insultante fortuna, o levantar las armas contra un piélago de calamidades y haciéndoles frente acabar con ellas?
\end{abstract}

Hamlet, William Shakespeare

La decisión, de diversos países, de no efectuar autopsias a los pacientes fallecidos por COVID-19 es probable que sea la estocada final a la patología postmortem en pediatría. Desde antes de la emergencia, la cantidad de autopsias en los hospitales académicos iba a la baja en muchos lugares.

A la fecha, solo existen dos reportes de autopsias pediátricas en el último año en Pub Med: ${ }^{1,2}$ uno de ellos tiene un resumen en inglés y el artículo completo en chino. ${ }^{1}$ Es un artículo escrito por patólogos forenses en el que refieren el hallazgo de displasia tímica en $21 \%$ de sus 61 pacientes. Por supuesto, también hacen hincapié en los hallazgos histopatológicos en pulmones, en los que resalta la mención de "formación de inclusiones virales". Para este hallazgo uno se queda reflexionando si se refieren a células gigantes multinucleadas con efecto citopático viral descrito en otras fuentes. Para el hallazgo de la displasia tímica, la reflexión es si esos pacientes tuvieron inmunodeficiencia primaria. Es probable que hayan sido autopsias completas, aunque poco puede asegurarse solo con el resumen.

El otro reporte mencionado corresponde a una autopsia completa en un paciente de 17 años, muerte al arribo, con SARS-CoV-2 demostrado por PCR en secreción nasofaríngea tomada postmortem, que tenía miocarditis eosinofílica fatal. ${ }^{2}$ Participan en la publicación patólogos pediatras, forenses y pediatras clínicos de Nueva Orléans.

\footnotetext{
Jefe del departamento de Anatomía Patológica.

Instituto Nacional de Pediatría, Ciudad de México.

Recibido: 6 de febrero 2020

Aceptado: 15 de mayo 2020

Correspondencia

Rodolfo Rodríguez-Jurado rrrj60@hotmail.com
}

Este artículo debe citarse como Rodríguez- Jurado R. Autopsia pediátrica en tiempos de la COVID-19 ¿ser o no ser?. Acta Pediatr Méx 2020; 41(5): 197-8.

DOI: 
Dado que el fallecimiento fue fulminante, los autores reflexionan acerca de la causa-efecto de SARS-CoV 2 en este paciente, en el entendido que hay ya varios casos descritos en población de mayor edad. ${ }^{3}$

El conocimiento es exiguo. Las nuevas herramientas para la autopsia molecular han entrado en juego en los centros donde se cuenta con ello. ${ }^{4}$ En el estudio de pulmones (solo pulmones en número de 7) de pacientes COVID-19, el estudio molecular fue relativo a los genes relacionados con la angiogénesis comparados con pulmones de pacientes que fallecieron por influenza (AH1N1) y un grupo control. Se regularon diferencialmente 69 genes relacionados con la angiogénesis, solo en el grupo COVID-19, comparados con solo 26 genes diferencialmente regulados solo en el grupo de influenza. 45 genes tuvieron cambios compartidos en expresión.

Visto en el plano morfológico, los pulmones de pacientes COVID compartieron con influenza el daño alveolar difuso y el infiltrado intersticial linfocitario. Hubo tres características angiocéntricas distintivas de la COVID-19: a) daño endotelial severo asociado con SARS-CoV 2 intracelular con daño en la membrana celular; $b$ ) trombosis diseminada con microangiopatía y oclusión de capilares alveolares; c) crecimiento de nuevos vasos a través de un mecanismo de angiogénesis intususceptiva. Noten que se estudiaron 7 pulmones de adultos con la COVID-19, cuando había 320,000 fallecimientos en Estados Unidos, sin contar los de Alemania, que participó en el estudio.

Las autopsias por COVID-19 deben contar con una serie de requerimientos y medidas para la protección del personal de salud. Hay dos artículos accesibles que resaltan dichas necesidades. ${ }^{5,6}$ Destaca la de una sala de autopsias con presión negativa, como la que se encuentra en algunos quirófanos. Por supuesto, el equipo de protección personal. No usar sierras eléctricas para la contención de aerosoles. La restricción en cantidad del personal encargado de la realización del estudio. El baño, cambio de ropa y calzado después de la evisceración y disección. En los hospitales académicos no parecen metas difíciles de lograr. La buena disposición de todo el personal implicado en lograrlo es decisiva.

Dr. Juan Rosai, maestro de Patología quirúrgica de muchas generaciones de patólogos en el mundo, recién fallecido, nos dio la opción del análisis póstumo como una medida para un estudio dirigido con preguntas específicas por resolver. ${ }^{7}$ Personalmente nunca estuve muy entusiasmado con esta opción; siempre hay hallazgos inesperados en una autopsia completa. Considero que la autopsia es el último estudio a profundidad que podemos ofrecer a nuestros pacientes. Ese estudio ha demostrado no solo su utilidad científica en enfermedades nuevas, sino el consuelo que otorga a la familia y al grupo médico que atendió al paciente.

\section{REFERENCIAS}

1. Chen Xue-bing, et al. Retrospective analysis of 61 cases of children died of viral pneumonia. Journal of Forensic Medicine. 2020; 36 (2): 164-168. 10.12116/j.issn.10045619.2020.02.003

2. Craver $\mathrm{R}$, et al. Fatal eosinophilic myocarditis in a healthy 17-year-old male with severe acute respiratory syndrome Coronavirus 2 (SARS-CoV-2c). Fetal Pediatric Pathol. 2020; 39 (3): 263-68. https://doi.org/10.1080/15513815.2020.1761491

3. Zhou F, et al. Clinical course and risk factors for mortality of adult inpatients with COVID-19 in Wuhan, China: a retrospective cohort study. Lancet. 2020; 395 (10229): 1054-62. doi:10.1016/S0140- 6736(20)30566-3.

4. Ackermann $\mathrm{M}$, et al. Pulmonary vascular endothelialitis, thrombosis, and angiogenesis in COVID-19. doi: 10.1056/ New Engl J Med oa2015432

5. Barton LM, et al. COVID-19 Autopsies, Oklahoma, USA . Am J Clin Pathol 2020; XX:1-9. doi: 10.1093/ajcp/aqaa062

6. Hanley B, et al. Autopsy in suspected COVID-19 cases. J Clin Pathol 2020; 73 (5): 239-42. doi:10.1136/jclinpath-2020-206522

7. Rosai J. The posthumous analysis (PHA). An alternative to the conventional autopsy. Am J Clin Pathol. 1996; 106 (4 Suppl 1): S15-7. 